\title{
Inhibitory effects of human neutrophil granules and oxygen radicals on adherence of Candida albicans
}

\author{
V.VUDDHAKUL, J.G. McCORMACK, W.K.SEOW and Y.H.THONG* \\ Immunobiology Laboratory, Departments of Child Health and Medicine, University of Queensland, Mater Public \\ Hospital, South Brisbane, Australia, 4101
}

\begin{abstract}
Summary. The adherence of Candida albicans to dacron fibre microcolumns was significantly suppressed after interaction with human neutrophils. The adherenceinhibiting properties of neutrophils were shown to reside in their cytoplasmic granules and granular enzymes. Oxygen-derived free radicals produced by the respiratory burst may also be responsible, as shown by experiments in which oxygen radicals were generated by the cell-free hypoxanthine-xanthine oxidase system. Dose-response studies with $\mathrm{H}_{2} \mathrm{O}_{2}$ and $\beta$-glucoronidase demonstrated that lower concentrations of these agents inhibited adherence without affecting viability of $C$. albicans. These results suggest that interference with adherence mechanisms may be an effective means of host defence by neutrophils against the colonisation of mucosal surfaces by C. albicans.
\end{abstract}

\section{Introduction}

Candida albicans is an opportunist microbial pathogen that causes a spectrum of infections from localised, self-limiting lesions of skin or mucous membranes to fatal disseminated disease. Although its invasive mechanisms are not well understood, the capacity to adhere to host cells, prosthetic devices and catheters represents a crucial early event in the pathogenesis of infection (Sobel et al., 1981; Lee and King, 1983; Shepherd et al., 1985; Rotrosen et al., 1986). The central role of neutrophils in defence against candida infection has been documented by in-vitro studies and clinical observations (Bodey, 1966; Kirkpatrick et al., 1971; Lehrer and Cline, 1971; Lehrer et al., 1975). This defence is mediated by various candidacidal proteins and enzymes located in cytoplasmic granules, and oxygen radicals generated by the respiratory burst (Lehrer, 1972; Diamond et al., 1980; Gantz et al., 1985; Selstead et al., 1985). Interference with adherence mechanisms of $C$. albicans has not been investigated previously as a possible target for immunological attack, although it has been postulated as a possible mode of action of antifungal drugs (Vuddhakul et al., 1988). Therefore it was decided to examine the ability of neutrophils and their microbial constituents to interfere with the adherence of candida.

Received 26 Aug. 1988; revised version accepted 17 Nov. 1988. *Correspondence should be sent to Professor Y. H. Thong.

\section{Materials and methods}

\section{C. albicans}

A recent clinical isolate of $C$. albicans from the blood of a patient with an infected intravenous catheter, and designated P12282, was kindly provided by $\mathrm{Dr} \mathrm{M}$. Tilse, Department of Microbiology, Mater Public Hospital, and maintained in culture as previously described with minor modifications(Thong and Ferrante, 1978; Ferrante and Thong, 1979). The stock culture was maintained at $25^{\circ} \mathrm{C}$ in Sabouraud Dextrose Agar (SDA) slopes covered with paraffin. A loopful of stock culture was subcultured on SDA for $18 \mathrm{~h}$ at $37^{\circ} \mathrm{C}$, and then inoculated into SDA broth and incubated at $25^{\circ} \mathrm{C}$ for $18 \mathrm{~h}$. A sample was removed, washed twice and resuspended in Dulbecco's phosphate buffered saline with $\mathrm{Ca}^{++}$, and $\mathrm{Mg}^{++}+$ glucose $1 \%$ (DPBS, Flow Laboratories, Sydney, Australia), phosphate buffered saline (PBS), or normal (physiological) saline for the experiments.

\section{Neutrophil isolation}

Neutrophils were prepared from the heparinised blood of healthy volunteers by centrifugation on Mono-Poly Resolving Medium (Flow Laboratories) at $1000 \mathrm{~g}$ for $30 \mathrm{~min}$. Neutrophils of $>97 \%$ purity were recovered from the second band at the interface (Ferrante and Thong, 1980). The cells were washed twice and resuspended in either DPBS, PBS or normal saline and adjusted to the required concentration by counting in a Neubaur haemocytometer. 


\section{Neutrophil granules}

Neutrophils $\left(5 \times 10^{7}\right.$ cells $)$ in ice-cold relaxation buffer were disrupted by three bursts, each of $2 \mathrm{~s}$, with a Branson ultrasonicator (West et al., 1974). Nuclei and nongranular debris were removed by successive filtration through 5$\mu \mathrm{m}$ and $2-\mu \mathrm{m}$ membrane filters (Millipore). Granules were separated on discontinuous Percoll gradients (Borregaard et al., 1983) consisting of $4 \mathrm{ml}$ of Percoll, density $1.120 \mathrm{~g} / \mathrm{ml}$, layered under $4 \mathrm{ml}$ of Percoll, density 1.050 $\mathrm{g} / \mathrm{ml}$. Approximately $1.5 \mathrm{ml}$ of neutrophil extract was then applied to the top and the gradient was centrifuged at $4^{\circ} \mathrm{C}$ and $17000 \mathrm{~g}$ for $15 \mathrm{~min}$. Three distinct bands were formed-azurophil granules, specific granules and plasma membrane. The purity of these bands were ascertained by assay for $\beta$-glucuronidase activity, which is confined to azurophil granules (Seow et al., 1988). Percoll from each granule band was removed by centrifugation at $23000 \mathrm{~g}$ for $2 \mathrm{~h}$, and the granules were dispersed in PBS by six bursts, each of $5 \mathrm{~s}$, with a Branson ultrasonicator.

\section{Oxygen metabolites}

Oxygen radicals were generated in vitro by the hypoxanthine-xanthine oxidase cell-free system as previously described (Seow et al., 1988). Hypoxanthine (HX, Sigma, St Louis MO, USA) was dissolved in 0.1 M PBS. Xanthine oxidase (XO, Boehringer, Sydney, Australia) was dissolved in $2 \mathrm{M}$ ammonium sulphate. Experiments were performed with a mixture of $0.1 \mathrm{mM}$ hypoxanthine and $4 \mathrm{mU}$ of xanthine oxidase in $1 \mathrm{ml}$-volumes containing C. albicans at a final concentration of $5 \times 10^{6}$ yeast cells $/ \mathrm{ml}$. After incubation for $1 \mathrm{~h}$ at $37^{\circ} \mathrm{C}$, the cells were washed twice and adherence measured by the method described below.

\section{Adherence micro-assay}

This assay was performed as previously described (Seow et al., 1987c; Vuddhakul et al., 1988). Briefly, dacron fibre microcolumns were prepared by carefully weighing 10-mg lots of dacron fibre (Olympic General Products, Queensland, Australia) and placing them into 100- $\mu$ l disposable pipette tips (Stockwell Scientific, CA, USA) so as to occupy the middle $1.5 \mathrm{~cm}$ of the $5 \mathrm{~cm}$ length of the pipette tip. Each microcolumn so prepared can accommodate $100 \mu \mathrm{l}$ of the $C$. albicans suspension.

After pre-incubation of $C$. albicans suspensions with neutrophils, granule constituents, oxygen radicals or specific enzymes, $10-\mu \mathrm{l}$ volumes of $C$. albicans, at a concentration of $5 \times 10^{6} \mathrm{cells} / \mathrm{ml}$, were pipetted into the dacron fibre microcolumns and kept at room temperature in high humidity for $30 \mathrm{~min}$. The microcolumns were then placed on a specially constructed apparatus which applied a suction pressure of approximately $250 \mathrm{mbar}$ for $1 \mathrm{~min}$ as previously described (Thong and Currell, 1983). The effluents were collected in disposable test tubes and chilled in ice before quantitation of yeast cells with a Neubauer haemocytometer. Experiments were per- formed in triplicate and the results were calculated as follows:

$$
\text { Percentage adherence }=100-(\mathrm{Ce} / \mathrm{Co} \times 100)
$$

where $\mathrm{Co}$ is the original concentration of $C$. albicans applied, and $\mathrm{Ce}$ is the concentration recovered in the effluent.

\section{Fungal viability assay}

Viability of C. albicans after exposure to $\mathrm{H}_{2} \mathrm{O}_{2}$ or $\beta$ glucuronidase was assessed by colony counting (Hughes et al., 1987). Samples were removed and serially diluted in sterile saline, and $0.05-\mathrm{ml}$ volumes were spread on SDA plates. The samples were also checked by microscopy to exclude the possibility of aggregation of yeast cells which may contribute to error in this type of assay. Cultures were placed in incubators at $37^{\circ} \mathrm{C}$ for $24-48 \mathrm{~h}$, after which the number of viable colonies was counted. Experiments were performed in triplicate and results were expressed as mean (SD) $\%$ adherence.

\section{Statistical analysis}

All experimental results were analysed by the one-way Analysis of Variance (ANOVA). Where appropriate, further statistical analysis was performed by the multiple comparisons procedure devised by Newman-Keuls (Miller, 1981 ; Milliken and Johnson, 1984).

\section{Results}

\section{Effect of neutrophils on candida adherence}

Initially the ability of human neutrophils to inhibit the adherence of $C$. albicans was investigated. $C$. albicans suspensions, at a concentration of $1 \times 10^{7}$ cells $/ \mathrm{ml}$, were divided into three lots. One lot was mixed with an equal volume of unstimulated neutrophils $\left(1 \times 10^{7}\right.$ cells $\left./ \mathrm{ml}\right)$, another with neutrophils which had been stimulated for $30 \mathrm{~min}$ with phorbol myristate acetate (PMA, Sigma $0 \cdot 1 \mu \mathrm{g} / \mathrm{ml}$ ) (Seow et al., 1987b), and the third lot served as control to which PBS only was added. After incubation at $37^{\circ} \mathrm{C}$ for $30 \mathrm{~min}$, the neutrophils were lysed with sodium desoxycholate $2.5 \%$ (Diamond et al., 1978) and washed twice in PBS, and the adherence of candida was determined. Preliminary experiments showed that this concentration of sodium desoxycholate has no effect on yeast adherence. The results (table I) show that unstimulated neutrophils significantly suppressed the adherence of candida $(p<0.05)$. Neutrophils stimulated by PMA caused an even greater suppression of yeast adherence $(\mathrm{p}<0.01)$ compared to control (saline) preparations. 
Table I. Effect of human neutrophils on the adherence of C.albicans

\begin{tabular}{c|ccc}
\hline & \multicolumn{3}{|c}{ Mean (SD) adherence (\%) of } \\
\cline { 2 - 4 } $\begin{array}{c}\text { Experiment } \\
\text { no. }\end{array}$ & $\begin{array}{c}\text { C. albicans } \\
\text { alone }\end{array}$ & $\begin{array}{c}\text { C. albicans } \\
\text { and neutro- } \\
\text { phils }\end{array}$ & $\begin{array}{c}\text { C. albicans and } \\
\text { PMA-stimulated } \\
\text { neutrophils }\end{array}$ \\
\hline 1 & $54 \cdot 6(5 \cdot 4)$ & $45 \cdot 6(3 \cdot 8)$ & $31 \cdot 7(4 \cdot 6)$ \\
2 & $61 \cdot 3(5 \cdot 0)$ & $48 \cdot 5(2 \cdot 9)$ & $38 \cdot 7(2 \cdot 5)$ \\
3 & $50 \cdot 4(2 \cdot 3)$ & $39 \cdot 2(4 \cdot 5)$ & $29 \cdot 7(5 \cdot 5)$ \\
\hline
\end{tabular}

The final concentrations of neutrophils and $C$. albicans were $5 \times 10^{6} / \mathrm{ml}$ (ratio $1: 1$ ). Incubation time was $1 \mathrm{~h}$ at $37^{\circ} \mathrm{C}$. PMA-

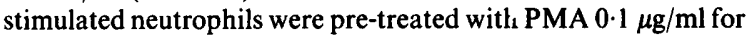
30 min before interaction with C. albicans. Each experiment was performed in triplicate with neutrophils from separate individuals.

Statistical analysis by one-way ANOVA shows significant inhibition of adherence by human neutrophils $(p<0.01, F$ test). The multiple comparisons test (Newman-Keuls) showed that PMA-stimulated neutrophils has greater inhibitory effects than unstimulated neutrophils $(\mathrm{p}<0.05)$.

\section{Effect of specific and azurophil granules}

In the next set of experiments, the two main types of neutrophil granules were isolated and examined for their capacity to inhibit the adherence of candida. Suspensions of C. albicans $\left(1 \times 10^{7}\right.$ cells $/$ $\mathrm{ml})$ were incubated with equal volumes of either specific or azurophil granules for $60 \mathrm{~min}$, washed twice in PBS, and adherence was then measured. The results (table II) show that, while both types of

Table II. Effect of neutrophil cytoplasmic granules on the adherence of $C$. albicans

\begin{tabular}{c|ccc}
\hline & \multicolumn{3}{|c}{ Mean (SD) adherence (\%) } \\
\cline { 2 - 4 } & & \multicolumn{3}{c}{ C. albicans treated with } \\
\cline { 2 - 4 } $\begin{array}{c}\text { Experiment } \\
\text { no. }\end{array}$ & Untreated & specific & azurophil \\
& C. albicans & granules & granules \\
\hline 1 & $64 \cdot 4(4 \cdot 7)$ & $57 \cdot 2(5 \cdot 2)$ & $45 \cdot 6(5 \cdot 6)$ \\
2 & $56 \cdot 3(5 \cdot 4)$ & $42 \cdot 1(4 \cdot 4)$ & $37 \cdot 2(4 \cdot 6)$ \\
3 & $54 \cdot 1(5 \cdot 0)$ & $40 \cdot 4(2 \cdot 1)$ & $27 \cdot 9(7 \cdot 5)$ \\
4 & $67 \cdot 0(3 \cdot 7)$ & $50 \cdot 5(3 \cdot 2)$ & $45 \cdot 3(5 \cdot 7)$ \\
\hline
\end{tabular}

C. albicans was treated with specific or azurophil granules for $1 \mathrm{~h}$ at $37^{\circ} \mathrm{C}$ before assay of adherence. Each experiment was performed in triplicate with neutrophil granules from separate donors.

Statistical analysis by one-way ANOVA showed significant inhibition of yeast adherence by neutrophil granules $(\mathrm{p}<0.01$, $F$ test), with greater inhibition by azurophil granules $(\mathrm{p}<0.05$, Newman-Keuls). granules are capable of suppressing adherence, greater inhibition of adherence was observed with azurophilic $(\mathrm{p}<0.01)$ than with specific granules $(\mathrm{p}<0.05)$.

Confirmation of these results was provided by experiments with pure lysozyme prepared from egg-white (Sigma) and $\beta$-glucuronidase (Boehringer, Sydney). These neutrophil granular enzymes were also capable of suppressing the adherence of candida $(\mathrm{p}<0.01)$ whereas heat-inactivated enzymes were ineffective (table III).

\section{Effect of oxygen metabolites}

The effects of oxygen-derived free radicals on yeast adherence are shown in table IV. Incubation of $C$. albicans with a mixture of hypoxanthine (HX) and xanthine oxidase (XO) resulted in a significant reduction in candida adherence $(p<0 \cdot 01)$. No inhibition of adherence was observed for C. albicans treated with either $\mathrm{HX}$ or XO alone. Known oxygen-radical scavengers such as superoxide dismutase (SOD, Sigma), catalase (Boehringer), dimethyl-sulfoxide (DMSO, Boehringer) and tetrandrine (Seow et al., 1988) were able to reverse the inhibition caused by HX and XO (tables V and VI). Heat-inactivation of SOD and catalase rendered them ineffective in this regard (tables $\mathrm{V}$ and VI).

\section{Adherence-inhibition and fungal viability}

C. albicans was subjected to varying concentrations of either $\mathrm{H}_{2} \mathrm{O}_{2}$ or $\beta$-glucuronidase to determine whether inhibition of yeast adherence occurs without impairment of fungal viability. The results (table VII) show dose dependent inhibition of both yeast adherence and viability. However, lower concentrations of either $\mathrm{H}_{2} \mathrm{O}_{2}$ or $\beta$-glucuronidase caused significant inhibition of adherence without affecting viability.

\section{Discussion}

The fungicidal properties of neutrophil leucocytes are known to reside in their cytoplasmic granules and in oxygen-derived free radicals generated by the respiratory burst. It is also known that the hyphae of $C$. albicans have the capacity to stimulate the respiratory burst and degranulation by neutrophils without the intervention of serum opsonins (Diamond and Krzesicki, 1978; Diamond et al., 1978; Lyman et al., 1987). This is particularly relevant to colonisation of the mucosa by $C$. albicans because serum opsonins are only present in minute 
Table III. Effect of enzymes found in neutrophil granules on the adherence of C. albicans

\begin{tabular}{|c|c|c|c|c|c|}
\hline \multirow[b]{4}{*}{ Experiment no. } & \multicolumn{5}{|c|}{ Mean (SD) adherence $(\%)$ of } \\
\hline & \multirow{3}{*}{$\begin{array}{l}\text { Untreated } \\
\text { C. albicans }\end{array}$} & \multicolumn{4}{|c|}{ C. albicans treated with } \\
\hline & & \multicolumn{2}{|c|}{ Lysozyme } & \multicolumn{2}{|c|}{$\beta$-glucuronidase } \\
\hline & & native & heated & native & heated \\
\hline $\begin{array}{l}1 \\
2 \\
3\end{array}$ & $\begin{array}{l}48 \cdot 1(3 \cdot 1) \\
61 \cdot 8(4 \cdot 2) \\
55 \cdot 1(3 \cdot 2)\end{array}$ & $\begin{array}{l}32 \cdot 3(3 \cdot 4) \\
40 \cdot 8(3 \cdot 8) \\
39 \cdot 0(3 \cdot 5)\end{array}$ & $\begin{array}{l}45 \cdot 7(4 \cdot 0) \\
59 \cdot 8(4 \cdot 1) \\
50 \cdot 4(3 \cdot 3)\end{array}$ & $\begin{array}{l}30 \cdot 1(4 \cdot 0) \\
21 \cdot 3(2 \cdot 5) \\
22 \cdot 9(5 \cdot 9)\end{array}$ & $\begin{array}{l}47 \cdot 2(4 \cdot 9) \\
62 \cdot 4(9 \cdot 2) \\
53 \cdot 3(6 \cdot 9)\end{array}$ \\
\hline
\end{tabular}

C. albicans was pre-treated with native or heat-treated $\left(65^{\circ} \mathrm{C}\right.$ for $\left.30 \mathrm{~min}\right)$ enzymes for $1 \mathrm{~h}$ at $37^{\circ} \mathrm{C}$ before assay of yeast adherence. Each of the experiments was performed in triplicate on separate occasions.

Statistical analysis by one-way ANOVA and Newman-Keuls showed significant inhibition of yeast adherence by native but not heat-inactivated enzymes $(\mathrm{p}<0.01)$.

Table IV. Effect of oxygen-derived free-radicals on the adherence of $C$. albicans

\begin{tabular}{c|cccc}
\hline & \multicolumn{4}{|c}{ Mean (SD) adherence (\%) of } \\
\cline { 2 - 5 } $\begin{array}{c}\text { Experi- } \\
\text { ment } \\
\text { no. }\end{array}$ & Untreated & \multicolumn{3}{c}{ C.albicans treated with } \\
\cline { 2 - 5 } & C. albicans & HX & XO & HX +XO \\
\hline 1 & $59 \cdot 3(4 \cdot 2)$ & $50 \cdot 3(7 \cdot 4)$ & $53 \cdot 9(4 \cdot 2)$ & $24 \cdot 4(12 \cdot 4)$ \\
2 & $48 \cdot 5(2 \cdot 4)$ & $49 \cdot 2(8 \cdot 2)$ & $50 \cdot 9(1 \cdot 2)$ & $30 \cdot 7(4 \cdot 5)$ \\
3 & $43 \cdot 2(4 \cdot 6)$ & $45 \cdot 8(2 \cdot 7)$ & $42 \cdot 0(2 \cdot 3)$ & $22 \cdot 0(5 \cdot 5)$ \\
& & & & \\
\hline
\end{tabular}

C. albicans was incubated with hypoxanthine (HX), xanthine oxidase (XO) or a combination of $\mathrm{HX}$ and $\mathrm{XO}$ for $1 \mathrm{~h}$ at $37^{\circ} \mathrm{C}$ before assay of adherence. Each experiment was performed in triplicate on separate occasions.

One-way ANOVA and Newman-Keuls analysis showed significant inhibition by the combination of $\mathrm{HX}$ and $\mathrm{XO}$ $(\mathrm{p}<0.01)$. quantities on mucosal surfaces (Clagett and Page, 1978; Hsu and Cole, 1985). Secretory $\operatorname{IgA}$ is the predominant antibody in secretions, but it is not opsonic (Underdown and Schiff, 1986).

The results of the present study show that the yeast form of $C$. albicans, after brief contact with human neutrophils and in the absence of serum opsonins, has a significantly reduced capacity to adhere to dacron fibres. As the yeast form of $C$. albicans is the predominant morphologic entity on mucosal surfaces, the suppression of yeast adherence may have implications for host resistance to colonisation by this dimorphic fungus. Later experiments demonstrated that both neutrophil granules and their enzyme constituents have adherenceinhibiting properties. Several individual constituents of neutrophils have been identified as having fungicidal properties, including cationic proteins,

Table V. Inhibition of $C$. albicans adherence by oxygen radicals and reversal by natural scavengers

\begin{tabular}{|c|c|c|c|c|c|c|}
\hline \multirow[b]{3}{*}{$\begin{array}{c}\text { Experiment } \\
\text { no. }\end{array}$} & \multicolumn{6}{|c|}{ Mean (SD) adherence $(\%)$ of } \\
\hline & \multirow[b]{2}{*}{$\begin{array}{l}\text { Untreated } \\
\text { C. albicans }\end{array}$} & \multicolumn{5}{|c|}{ C. albicans treated with } \\
\hline & & $\mathrm{HX}+\mathrm{XO}$ & $\begin{array}{c}\mathrm{HX}+\mathrm{XO} \\
\mathrm{SOD}(\mathrm{n})\end{array}$ & $\begin{array}{c}\mathrm{HX}+\mathrm{XO} \\
\text { SOD (i) }\end{array}$ & $\begin{array}{c}\mathrm{HX}+\mathbf{X O} \\
\text { catalase }(\mathrm{n})\end{array}$ & $\begin{array}{c}\mathrm{HX}+\mathrm{XO} \\
\text { catalase (i) }\end{array}$ \\
\hline 1 & $66 \cdot 8(9 \cdot 3)$ & $34 \cdot 2(5 \cdot 3)$ & $53.9(6 \cdot 5)$ & $24 \cdot 5(5 \cdot 9)$ & $61 \cdot 5(4 \cdot 9)$ & $28 \cdot 4(6 \cdot 5)$ \\
\hline 2 & $60 \cdot 9(6 \cdot 2)$ & $23 \cdot 2(3.9)$ & $55 \cdot 7(8.9)$ & $27 \cdot 0(3 \cdot 6)$ & $52 \cdot 5(5 \cdot 7)$ & $35 \cdot 7(5 \cdot 1)$ \\
\hline 3 & $49 \cdot 7(5 \cdot 1)$ & $31 \cdot 4(6 \cdot 9)$ & $45 \cdot 2(2 \cdot 3)$ & $35.9(4.9)$ & $47 \cdot 3(5 \cdot 5)$ & $29 \cdot 4(7 \cdot 3)$ \\
\hline
\end{tabular}

C. albicans was incubated with the combination of hypoxanthine (HX) and xanthine oxidase (XO) for $1 \mathrm{~h}$ at $37^{\circ} \mathrm{C}$ before assay of adherence. The reaction mixture also contained superoxide dismutase (SOD) or catalase, in the native $(\mathrm{n})$ or the heat-inactivated $\left(\mathrm{i}, 65^{\circ} \mathrm{C}\right.$ for $30 \mathrm{~min}$ ) forms. Experiments were performed in triplicate on separate occasions.

One-way ANOVA and Newman-Keuls statistical analysis showed reversal of adherence inhibition in the presence of native SOD and catalase $(p<0.01)$, but not with the heat-inactivated forms. 
Table VI. Inhibition of $C$. albicans adherence by oxygen radicals and reversal by anti-oxidants

\begin{tabular}{c|cccc}
\hline & \multicolumn{4}{|c}{ Mean (SD) Adherence (\%) of } \\
\cline { 2 - 5 } & & \multicolumn{4}{c}{ C. albicans treated with } \\
\cline { 2 - 5 } Experi- & $\begin{array}{c}\text { Untreated } C . \\
\text { albicans }\end{array}$ & HX+XO & HX+XO & HX+XO \\
ment no. & & DMSO & TT \\
\hline 1 & $53 \cdot 1(8.9)$ & $23.9(3.0)$ & $42 \cdot 8(4 \cdot 4)$ & $38 \cdot 2(6.5)$ \\
2 & $60 \cdot 1(5 \cdot 1)$ & $38.7(5 \cdot 1)$ & $54.9(6.7)$ & $53.9(7.4)$ \\
3 & $57 \cdot 1(7.6)$ & $36.5(3.5)$ & $60 \cdot 4(4 \cdot 8)$ & $52 \cdot 5(6.8)$ \\
\hline
\end{tabular}

C. albicans was incubated with a combination of hypoxanthine (HX) and xanthine oxidase (XO) in the presence of dimethylsulphoxide (DMSO) or tetrandrine (TT), for $1 \mathrm{~h}$ at $37^{\circ} \mathrm{C}$ before assay of adherence. Experiments were performed in triplicate on separate occasions.

Statistical analysis by one-way ANOVA and Newman-Keuls showed significant reversal of adherence inhibition by DMSO and TT $(\mathrm{p}<0.01)$.

peptides and some enzymes (Lehrer et al., 1975; Lehrer and Ladra, 1977; Gantz et al., 1985). It was decided to use lysozyme, found in both specific and azurophil granules, and $\beta$-glucuronidase, present in azurophil granules only, because their mechanisms of action are well defined. Thus lysozyme has been noted to cause an increase in permeability of the fungal cell membrane (Collins and Pappagianis, $1974 a, b)$, whereas $\beta$-glucuronidase is believed to cause degradation of oligosaccharides in the fungal cell wall (Podhradsky et al., 1982). The experiments also showed that oxygen radicals produced by the hypoxanthine-xanthine oxidase reaction are also capable of suppressing the adherence of candida and that this suppression can be reversed by a number of antioxidants and oxygen radical scavengers. With known concentrations of enzyme or oxygen radicals, we showed, in subsequent experiments, that the concentrations required for inhibition of adherence were much less than those needed for killing C. albicans.

Since dacron fibres, a synthetic material, was used to measure candida adherence in these studies, the clinical relevance of our data to candidal colonisation of dentures and indwelling catheters may be inferred. Whether or not there is relevance to candida infection of mucosal surfaces is unclear, although there is some evidence to suggest that the same "adhesin" mechanism of $C$. albicans may be involved, and that there may be a correlation between adherence to plastic materials and to mucosal surfaces (Samaranayake and MacFarlane, 1980; Samaranayake et al., 1980; Minagi et al., 1985; Rotrosen et al., 1986).

These results suggest that the adherence mechanism of $C$. albicans may be a feasible target for immunological attack by neutrophils, and since less energy and materials are needed for adherence inhibition than for fungicidal activity, this may be an effective method of host defence against the colonisation of mucosal surfaces by $C$. albicans. In

Table VII. Effect of $\mathrm{H}_{2} \mathrm{O}_{2}$ and $\beta$-glucuronidase on C. albicans adherence and viability

\begin{tabular}{|c|c|c|c|c|c|c|}
\hline \multirow[b]{2}{*}{$\mathrm{H}_{2} \mathrm{O}_{2}$ concentration $(\mu \mathrm{M})$} & \multicolumn{2}{|c|}{ Experiment no. 1} & \multicolumn{2}{|c|}{ Experiment no. 2} & \multicolumn{2}{|c|}{ Experiment no. 3} \\
\hline & adherence & viability & adherence & viability & adherence & viability \\
\hline 0 & $52 \cdot 8(8 \cdot 8)$ & $6 \cdot 5(1 \cdot 5)$ & $73 \cdot 5(4 \cdot 3)$ & $6.8(0.6)$ & $59 \cdot 5(6 \cdot 8)$ & $2 \cdot 6(0 \cdot 8)$ \\
\hline 1 & $48 \cdot 7(5 \cdot 5)$ & $5 \cdot 7(0 \cdot 9)$ & $72 \cdot 1(2 \cdot 6)$ & $6 \cdot 8(0.8)$ & $58 \cdot 3(6 \cdot 1)$ & $2 \cdot 6(0 \cdot 3)$ \\
\hline 10 & $40 \cdot 4(6 \cdot 1)$ & $5 \cdot 2(1 \cdot 7)$ & $65 \cdot 6(4 \cdot 2)$ & $6 \cdot 0(0 \cdot 3)$ & $50 \cdot 1(2 \cdot 6)$ & $2 \cdot 5(0 \cdot 7)$ \\
\hline 100 & $17 \cdot 0(6 \cdot 0)$ & $3.9(1.4)$ & $40 \cdot 3(3 \cdot 7)$ & $5 \cdot 0(1 \cdot 1)$ & $21 \cdot 2(8 \cdot 0)$ & $1 \cdot 7(0 \cdot 1)$ \\
\hline 500 & $3 \cdot 3(3 \cdot 6)$ & $1 \cdot 4(0 \cdot 5)$ & $11 \cdot 6(3 \cdot 1)$ & $2 \cdot 6(0 \cdot 8)$ & $9 \cdot 3(5 \cdot 9)$ & $0.4(0.3)$ \\
\hline \multicolumn{7}{|l|}{$\begin{array}{l}\beta \text {-glucuronidase concentra- } \\
\text { tion }(\mathrm{U} / \mathrm{ml})\end{array}$} \\
\hline 0 & $60 \cdot 1(4 \cdot 8)$ & $5 \cdot 4(0 \cdot 8)$ & $65 \cdot 6(5 \cdot 5)$ & $2 \cdot 9(1 \cdot 0)$ & $50 \cdot 7(4 \cdot 5)$ & $4 \cdot 2(0 \cdot 8)$ \\
\hline 5 & $57 \cdot 9(4 \cdot 3)$ & $5 \cdot 0(1 \cdot 1)$ & $61 \cdot 7(4 \cdot 7)$ & $2 \cdot 8(0 \cdot 8)$ & $48 \cdot 1(3 \cdot 9)$ & $4 \cdot 0(0 \cdot 3)$ \\
\hline 10 & $30 \cdot 0(1 \cdot 6)$ & $4 \cdot 2(0 \cdot 5)$ & $44 \cdot 9(5 \cdot 7)$ & $1.9(0.4)$ & $36 \cdot 5(4 \cdot 4)$ & $3 \cdot 4(0 \cdot 3)$ \\
\hline 20 & $19 \cdot 4(5 \cdot 6)$ & $4 \cdot 1(0 \cdot 7)$ & $25 \cdot 0(4 \cdot 1)$ & $1 \cdot 5(0 \cdot 4)$ & $20 \cdot 5(3 \cdot 7)$ & $3 \cdot 0(0.6)$ \\
\hline 40 & $9 \cdot 1(4 \cdot 9)$ & $3 \cdot 0(0 \cdot 3)$ & $13 \cdot 9(4 \cdot 6)$ & $0.6(0.3)$ & $10 \cdot 4(3 \cdot 2)$ & $1 \cdot 1(0 \cdot 4)$ \\
\hline
\end{tabular}

C. albicans was incubated with $\mathrm{H}_{2} \mathrm{O}_{2}$ or $\beta$-glucuronidase for $1 \mathrm{~h}$ at $37^{\circ} \mathrm{C}$ before the simultaneous assays for adherence and viability. Experiments were performed in triplicate and results expressed as mean percentage (SD) adherence or viability. Each experiment was performed on separate occasions.

One-way ANOVA and Newman-Keuls statistical analysis showed significant inhibition of yeast adherence at lower concentrations of $\mathrm{H}_{2} \mathrm{O}_{2}$ or $\beta$-glucuronidase compared to yeast viability. 
this regard, there is increasing evidence to suggest that neutrophils play a significant role in defence at mucosal surfaces (Attstrom and Egelberg, 1970; Scully and Challacombe, 1979; Seow et al., 1987a, $b$; Tsuda et al., 1983; Weiss et al., 1983).

The nature of adherence mechanisms in $C$. albicans is not as well understood as that of bacteria (Beachy, 1981) but may involve mannoprotein adhesins (McCourtie and Douglas, 1981). These cell wall structures appear to be as susceptible to immunological attack as they are to chemothera-

\section{REFERENCES}

Attstrom R, Egelberg J 1970 Emigration of blood neutrophils and monocytes into the gingival crevices. Journal of Periodontal Research 5: 48-55.

Beachey E H 1981 Bacterial adherence: adhesin-receptor interactions mediating the attachment of bacteria to mucosal surfaces. Journal of Infectious Diseases 143: 325345.

Bodey G P 1966 Fungal infections complicating acute leukemia. Journal of Chronic Diseases 19: 667-687.

Borregaard N, Heiple J M, Simons E R, Clark R A 1983 Subcellular localization of the $\beta$-cytochrome component of the human neutrophil microbicidal oxidase: translocation during activation. Journal of Cell Biology 97 : 52-61.

Clagett J A, Page R C 1978 Insoluble immune complexes and chronic periodontal disease in man and the dog. Archives of Oral Biology 23: 153-165.

Collins M S, Pappagianis D 1974a Inhibition by lysozyme of growth of the spherule phase of Coccidioides immitis in vitro. Infection and Immunity 10: 616-623.

Collins M S, Pappagianis D $1974 b$ Lysozyme-enhanced killing of Candida albicans and Coccidioides immitis by amphoteracin B. Sabouraudia 12: 329-340.

Diamond R D, Clark R A, Haudenschild C C 1980 Damage to Candida albicans hyphae and pseudohyphae by the myeloperoxidase system and oxidative products of neutrophil metabolism in vitro. Journal of Clinical Investigation 66: 908917.

Diamond R D, Krzesicki R 1978 Mechanisms of attachment of neutrophils to Candida albicans pseudohyphae in the absence of serum, and of subsequent damage to pseudohyphae by microbial processes of neutrophils in vitro. Journal of Clinical Investigation 61 : 360-369.

Diamond R D, Krzesicki R, Jao W 1978 Damage to pseudohyphal forms of Candida albicans by neutrophils in the absence of serum in vitro. Journal of Clinical Investigation 61 : 349-359.

Ferrante A, Thong Y H 1979 Requirement of heat-labile opsonins for maximal phagocytosis of Candida albicans. Sabouraudia 17: 293-297.

Ferrante A, Thong Y H 1980 Optimal conditions for the simultaneous purification of mononuclear and polymorphonuclear leukocytes from human blood by the HypaqueFicoll method. Journal of Immunological Methods 36: 109117.

Gantz T, et al. 1985 Defensins: natural peptide antibiotics of human neutrophils. Journal of Clinical Investigation 76: 1427-1435.

Hsu S D, Cole M F 1985 Structural integrity of host defense peutic attack (Vuddhakul et al., 1988). Since adherence is a universal mechanism of pathogenesis for most microbes, further studies along these lines may offer additional insights into host-parasite interactions and antifungal therapy.

This work was supported in part by grants from the J.P. Kelly Foundation (Mater Hospital), and the Mayne Bequest Fund (University of Queensland). V.V. is the recipient of a scholarship from the Australian International Development Assistance Bureau, Canberra.

factors in dental plaque. Infection and Immunity 50: 398402.

Hughes C E, Bennett R L, Beggs W H 1987 Broth dilution testing of Candida albicans susceptibility to ketoconazole. Antimicrobial Agents and Chemotherapy 31 : 643-646.

Kirkpatrick C H, Green I, Rich R R, Schade A I 1971 Inhibition of growth of Candida albicans by iron unsaturated lactoferrin: relation to host-defense mechanisms in chronic mucocutaneous candidiasis. Journal of Infectious Diseases 124: 539-544.

Lee J C, King R D 1983 Characterization of adherence of Candida albicans to human vaginal epithelial cells in vitro. Infection and Immunity 41 : 1024-1030.

Lehrer R I 1972 Functional aspects of a second mechanism of candidacidal activity by human neutrophils. Journal of Clinical Investigation 51 : 2566-2572.

Lehrer R I, Cline M J 1971 Leukocyte candidacidal activity and resistance to systemic candidiasis patients with cancer. Cancer 27: 1211-1217.

Lehrer R I, Ladra K M 1977 Fungicidal components of mammalian granulocytes active against Cryptococcus neoformans. Journal of Infectious Diseases 136: 96-99.

Lehrer R I, Ladra K M, Hake R B 1975 Non-oxidative fungicidal mechanisms of mammalian granulocytes: Demonstration of components with candidacidal activity in human, rabbit, and guinea pig leukocytes. Infection and Immunity 11: 12261234.

Lyman C A, Simons E R, Melnick D A, Diamond R D 1987 Unopsonized Candida albicans hyphae stimulate a neutrophil respiratory burst and a cytosolic calcium flux without membrane depolarization. Journal of Infectious Diseases 156: $770-776$.

McCourtie J, Douglas L J 1981 Relationship between cell surface composition of Candida albicans and adherence to acrylic after growth on different carbon sources. Infection and Immunity 32: 1234-1241.

MillerSL 1981 Introductory statistics for dentistry and medicine. Reston Publishing Company, Reston, VA.

Milliken G A, Johnson D E 1984 Analysis of messy data; vol 1: Designed experiments. (Lifetime Learning Publications), Van Nostrand Reinhold, New York.

Minagi S, Miyake Y, Inagaki K, Tsuru H, Suginaka H 1985 Hudrophobic interaction in Candida albicans and Candida tropicalis adherence to various denture base resin materials. Infection and Immunity 47, 11-14.

Podhradsky J, Jany J, Velgos S 1982 Beta-glucuronidase activity in human gingiva in health and periodontal disease. Archives of Oral Biology 27 : 615-616.

Rotrosen D, Calderone R A, Edwards J E 1986 Adherence of Candida species to host tissues and plastic surfaces. Reviews of Infectious Diseases 8: 73-85.

Samaranayake L P, MacFarlane T W 1980 An in-vitro study of 
the adherence of Candida albicans to acrylic surfaces. Archives of Oral Biology 25, 603-609.

Samaranayake L P, McCourtie J, MacFarlane T W 1980 Factors affecting the in-vitro adherence of Candida albicans to acrylic surfaces. Archives of Oral Biology 25, 611-615.

Scully C, Challacombe S J 1979 The migration of ${ }^{111}$ Indiumlabelled polymorphonuclear leucocytes into the oral cavity in the rhesus monkey. Journal of Periodontal Research 14: 475-481.

Selstead M E, Szklarek D, Gantz T, Lehrer R I 1985 Activity of rabbit leukocyte peptides against Candida albicans. Infection and Immunity 49: 202-206.

Seow W K, Ferrante A, Li SY, Thong Y H 1988 Antiphagocytic and antioxidant properties of plant alkaloid tetrandrine. International Archives of Allergy and Applied Immunology 85: 404-409.

Seow W K, Seymour G J, Thong Y H 1987a Modulatory effects of Streptococcus mutans on human neutrophil adherence and deoxyglucose uptake. International Archives of Allergy and Applied Immunology 82: 40-45.

Seow W K, Thong Y H, Ferrante A $1987 b$ Macrophageneutrophil interaction: contrasting effects of the monokines interleukin-1 and tumor necrosis factor (cachectin) on human neutrophil adherence. Immunology 62: 357-361.

Seow W K, Vuddhakul V, McCormack J G, Thong Y H $1987 c$ A simple rapid method for the microassay of adherence of Candida albicans to nylon fibre. Journal of Microbiological Methods 6: 167-175.

Shepherd M G, Poulter R T M, Sullivan P A 1985 Candida albicans: biology, genetics, and pathogenicity. Annual Review of Microbiology 39: 579-614.

Sobel J D, Myers P G, Kaye D, Levison M E 1981 Adherence of Candida albicans to human vaginal and buccal epithelial cells. Journal of Infectious Diseases 143: 76-82.

Thong Y H, Currell J M 1983 Development of a microassay technique for neutrophil adherence. Journal of Immunological Methods 63: 229-236.

Thong Y H, Ferrante A 1978 Alternative pathway of complement activation by Candida albicans. Australian and New Zealand Journal of Medicine 8: 620-622.

Tsuda H, Dickey W D, Goldman A S 1983 Separation of human colostral macrophages and neutrophils on gelatin and collagen-serum substrata. Cell Structure and Function 8: 367-71.

Underdown B J, Schiff J M 1986 Immunoglobulin A: strategic defence initiative at the mucosal surface. Annual Review of Immunology $4: 389-417$.

Vuddhakul V, McCormack J G, Seow W K, Smith S E, Thong Y H 1988. Inhibition of adherence of Candida albicans by conventional drugs. Journal of Antimicrobial Chemotherapy 21 : 755-764.

Weiss R A, Chanana A D, Joel D D 1983 Localized pulmonary neutrophil influx induced by lung lavage in sheep. Lung 161: 369-374.

West B C, Rosenthal A S, Gelb N A, Kimball H R 1974 Separation and characterization of human neutrophil granules. American Journal of Pathology 77: 41-66. 